\title{
Myocardial ischaemia due to stenosis of the subclavian artery
}

\author{
Maciej Lewandowski, Andrzej Modrzejewski, Jarosław Gorący, Zdzisława Kornacewicz-Jach \\ Department of Cardiology, Pomeranian Medical University, Szczecin, Poland
}

Videosurgery and other miniinvasive techniques 2011; 6 (2): 115-120 DOI: $10.5114 /$ wiitm.2011.23218

\begin{abstract}
The internal thoracic artery is often used for reconstruction of coronary arteries. In a proportion of cases the reason for bypass failure (internal thoracic artery - coronary artery) is abnormal blood flow in the subclavian artery resulting from its stenosis. The stricture can result from post-surgery progression of atherosclerosis or could have been present and undiagnosed already when cardiac surgery was performed. This may result in exercise angina or even acute coronary syndrome. Interventional intervention is inevitable in these cases. An 84-year-old man was admitted for unstable angina 7 years after coronary artery bypass grafting (CABG) from the internal thoracic artery to the left anterior descending branch of the left coronary artery. In spite of medical treatment the symptoms did not recede and coronary and bypass angiography was performed on the $4^{\text {th }}$ day of hospitalization, revealing multiple stenoses of the coronary arteries and severe stenosis of the left subclavian artery. Moreover, the symptoms subsided only slightly after angioplasty of the circumflex branch of the left coronary artery. For this reason, angioplasty of the left subclavian artery with stent implantation, widening of the right coronary artery aortic opening, and angioplasty of the left coronary artery trunk and of the circumflex branch at its origin were performed. These procedures resulted in complete cessation of angina, while the patient also observed significant improvement of his left upper limb performance. The coronary-subclavian steal syndrome is defined as reduced flow through the bypass (internal thoracic artery coronary artery) or reversed flow through the bypass, as a result of the narrowing of the proximal part of the left subclavian artery. In most cases the symptoms are stable and chronic, but in some patients an acute coronary syndrome can develop. Additionally, there are usually disturbances of the left upper limb perfusion. Routine blood pressure measurement on both arms is believed to identify a group of patients with high probability of subclavian artery stenosis, who may benefit from supplementation of coronary angiography with aortic arch imaging. Traditional surgical methods of treatment for subclavian-coronary steal syndrome include bypass between the left common carotid and left subclavian artery. However, intravascular angioplasty with stent implantation is a contemporary method of choice. Intravascular methods allow simultaneous correction of coronary vessels when there is a recurrent stenosis.
\end{abstract}

Key words: subclavian artery stenosis, bypass grafting, internal thoracic artery, coronary arteries.

\section{Introduction}

The left and right internal thoracic artery (LITA and RITA, respectively), a branch of the subclavian artery, is often used for reconstruction of coronary arteries. Long-term results of this treatment method are very good. Bypasses with internal thoracic artery remain patent after 10 years in $90 \%$ of cases. The results are peculiarly satisfactory in patients who underwent a bypass from the aforementioned vessel to the descending anterior branch of the left coronary artery $[1,2]$. In a proportion of bypass (internal thoracic-coronary artery) failure cases disturbances of blood flow in the subclavian artery due to its stenosis are observed [3]. This stricture may result from the progression of 
atheromatosis after the surgery. In some cases however, it can be assumed that a stenosis must have been present, yet unnoticed, already when the cardiac surgery was performed. Reduction of blood flow via the subclavian artery can limit the inflow into the bypass (thoracic internal-coronary artery), and hence cause exertion angina or even acute coronary syndrome. Such cases call for interventional treatment.

\section{Case report}

An 84-year-old man was admitted to the cardiology department of the regional hospital with symptoms of coronary disease. Angina associated with minor exercise (Canadian Cardiology Society class 3) had been present for 2 months already and symptoms during rest had manifested a few days prior to hospital admission. Eight years before the patient had suffered from anterior cardiac wall infarction followed by cardiac surgery a year later. The aorta was anastomosed with the right coronary artery with a venous bypass. A similar bypass connected the aorta to the marginal branch (originating at the circumflex artery) of the left coronary artery. Reconstruction of blood supply to the left coronary artery was achieved with a bypass from the internal thoracic to the anterior descending branch. Apart from signs of previous myocardial infarction of the anterior wall, discrete dynamic aberrances of ST recording from the

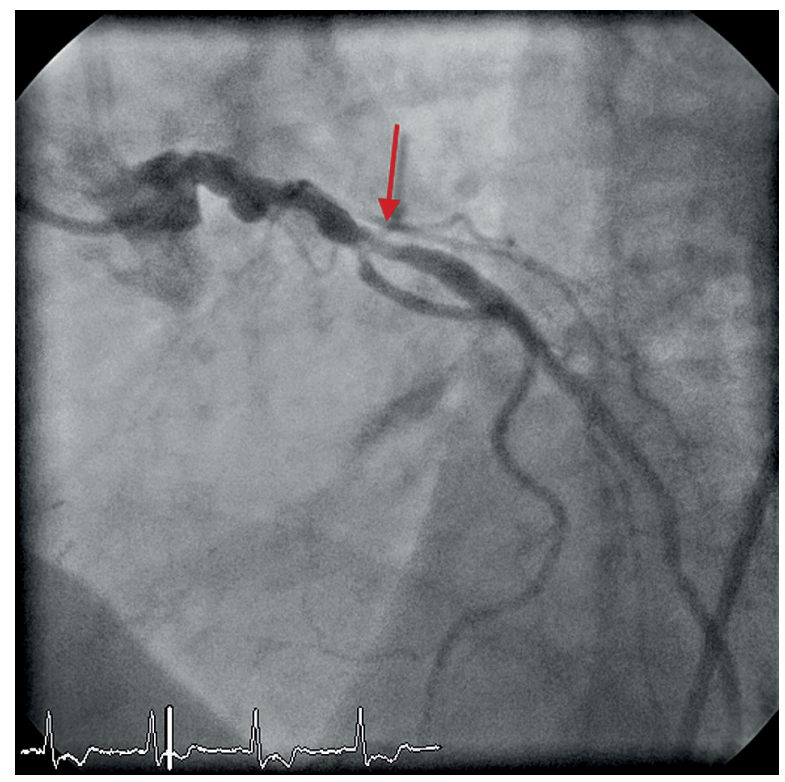

Figure 1. Severe stenosis of the circumflex branch of the left coronary artery lateral wall were present on an ECG recording. Cardiac ultrasound showed extensive contractility disorders, with total ejection fraction of the left ventricle of $25 \%$ and normal performance of the valves. Laboratory tests revealed a small increase of cardiac troponin activity (not significant for myocardial infarction). Risk factors of coronary disease included hypertension and hypercholesterolaemia. MDRD-calculated GFR was $49 \mathrm{ml} / \mathrm{min} / 1.73 \mathrm{~m}^{2}$.

In spite of the pharmacological treatment the symptoms did not resolve, and coronary angiography was performed on the $4^{\text {th }}$ day of hospitalization. The venous bypass from the aorta to the right coronary artery was occluded, and blood supply to the inferior wall of the left and right ventricle was via the right coronary artery, significantly stenosed in its first segment. In the area supplied by the left coronary artery, severe stricture of the marginal branch and occluded bypass from the aorta were found. The circumflex artery contained an asymmetric, unstable atheromatic plaque with signs of thrombosis (Figure 1). Additionally, an occluded anterior descending branch was discovered, which nearly completely, although with substantial delay, filled from the arterial bypass.

Effective angioplasty of the circumflex artery was performed (15 mm stent mounted on a $3.5 \mathrm{~mm}$ balloon) (Figure 2). Accessing the arterial bypass (internal thoracic - left coronary artery) was unsuccessful due to significant stenosis of the left subclavian artery. No

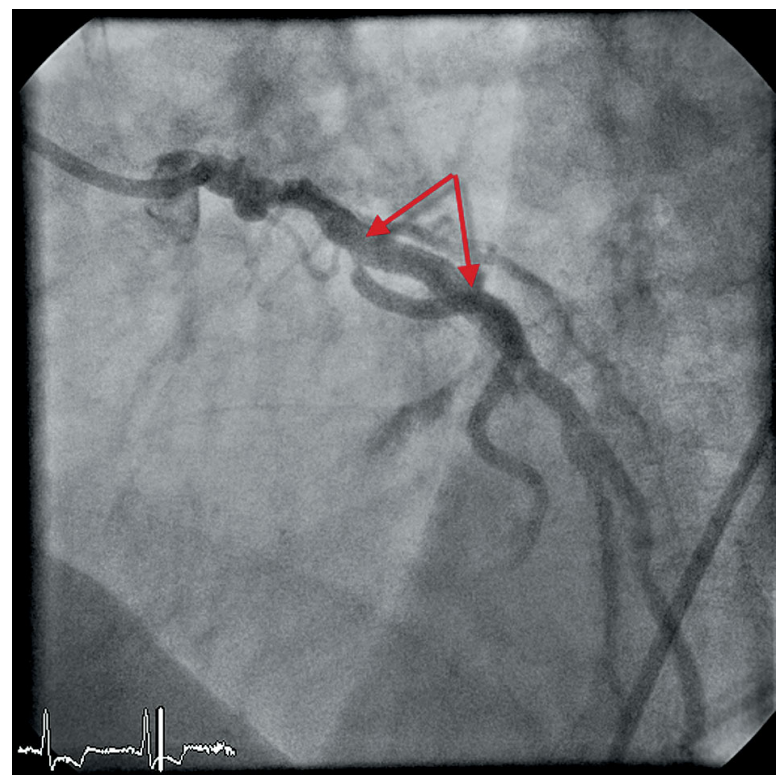

Figure 2. The circumflex branch after implantation of the stent at stenosis 
flow of contrast media via the left vertebral artery (originating from the subclavian artery) was found (Figure 3). Coronary symptoms did not resolve completely after this procedure. The patient was transferred to the Department of Cardiology of the Pomeranian Medial University in Szczecin. On admission, there was no pulse on the left radial artery, and no signs of congestive heart failure were present. Arterial blood pressure measured on the left and right brachial arteries was respectively 0 and 120/80 $\mathrm{mmHg}$. Anamnesis directed towards this finding revealed symptoms of upper limb ischaemia that included feeling cold and easy fatigue of this limb.

Angiography confirmed prior diagnosis of the condition of both the coronary circulation and subclavian artery. Subclavian artery angioplasty followed. The lesion was first widened with a $5 \mathrm{~mm}$ balloon catheter, and then a self-expanding Maris $10 \times$ $\times 30 \mathrm{~mm}$ (Invatec) stent was placed. The stent was deployed with a $9 \times 30 \mathrm{~mm}$ Fox Plus balloon catheter. Complete resolution of subclavian artery stenosis was achieved and immediate improvement of blood flow into the left internal thoracic artery, and hence to the descending branch of the left coronary artery, was observed. What is more, normal blood flow in the left vertebral artery was restored (Figures 4, 5).

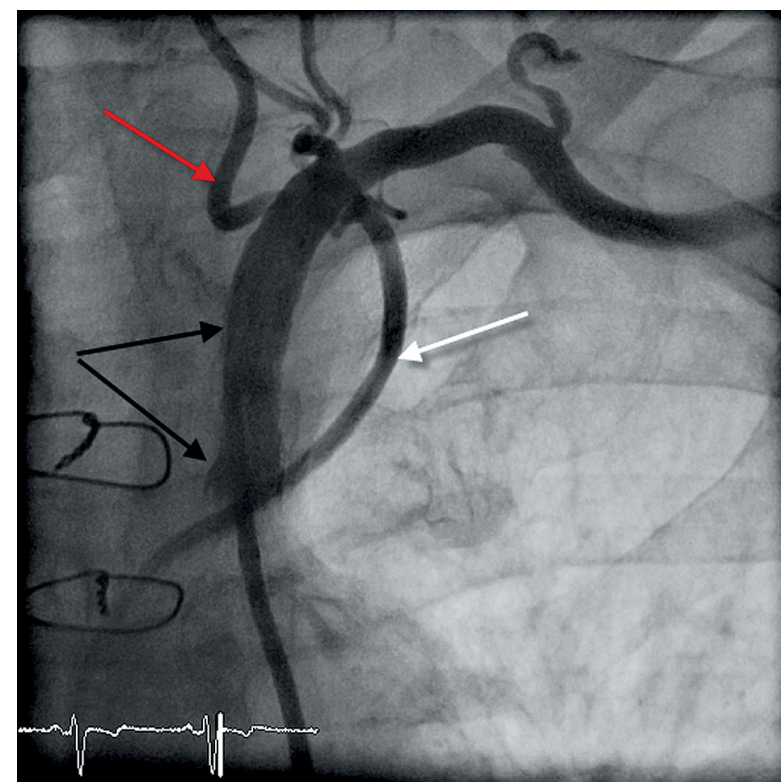

Figure 4. Left subclavian artery after stent implantation (black arrows). Well-contrasting vertebral (red arrow) and internal thoracic (white arrow) arteries
Additionally, the aortic ostium of the right coronary artery was expanded with a $3.5 \mathrm{~mm}$ metal stent placement (Figures 6,7 ), and the trunk of the left coronary artery and circumflex branch at its origin from the stem were corrected with a cobalt-chromium $4 \mathrm{~mm}$ stent (Figure 8).

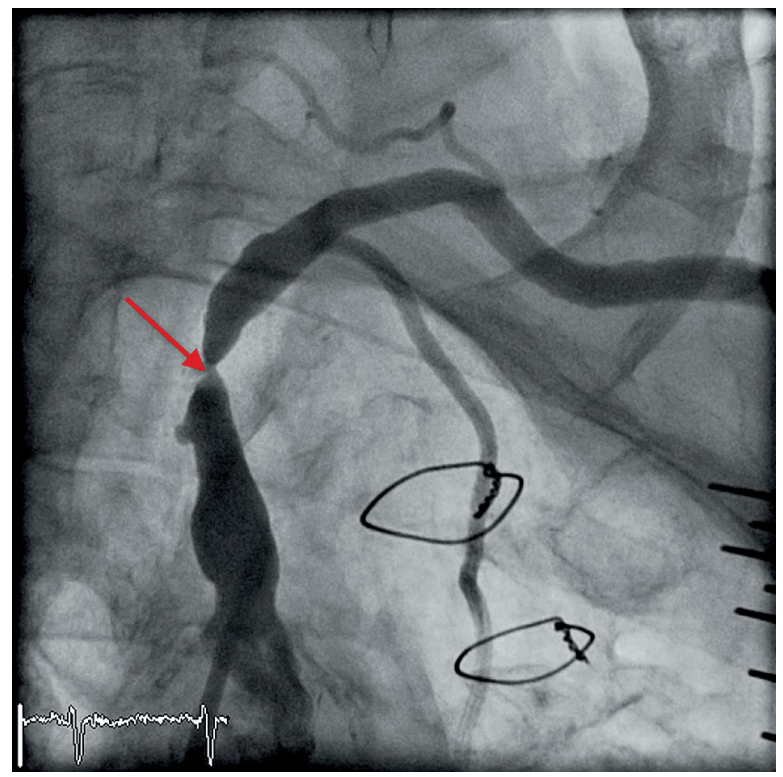

Figure 3. Significant stenosis of the left subclavian artery

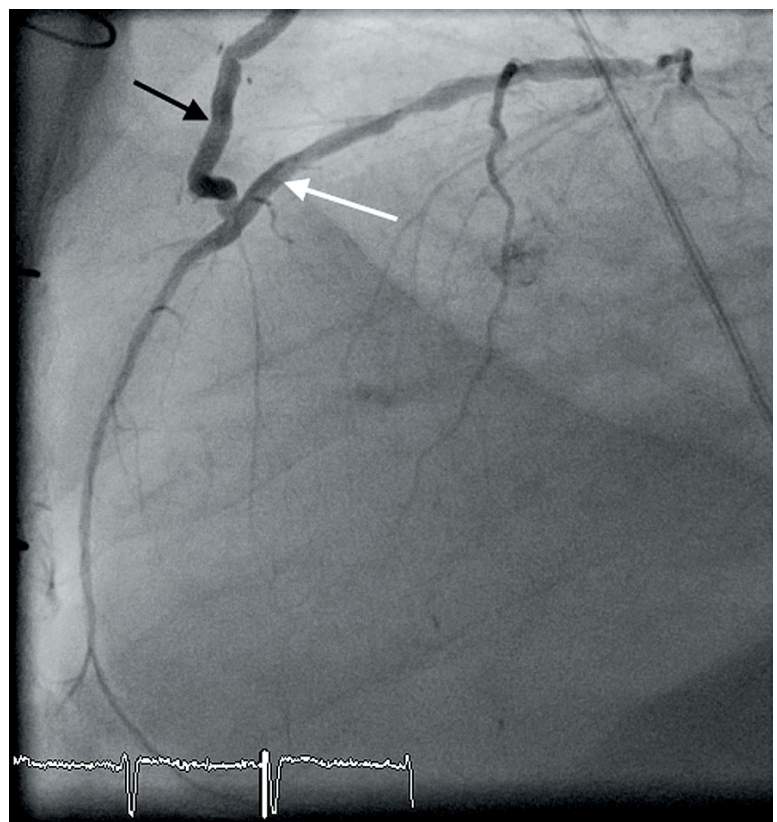

Figure 5. Descending anterior branch (white arrow) with satisfactory blood supply from the internal thoracic artery (black arrow) 
The procedure resulted in complete resolution of coronary symptoms and the patient noted significant improvement of the left arm performance as well. Blood pressure measured on each arm after intervention was $120 / 80 \mathrm{mmHg}$ on the right and $110 / 70 \mathrm{mmHg}$ on the left side.

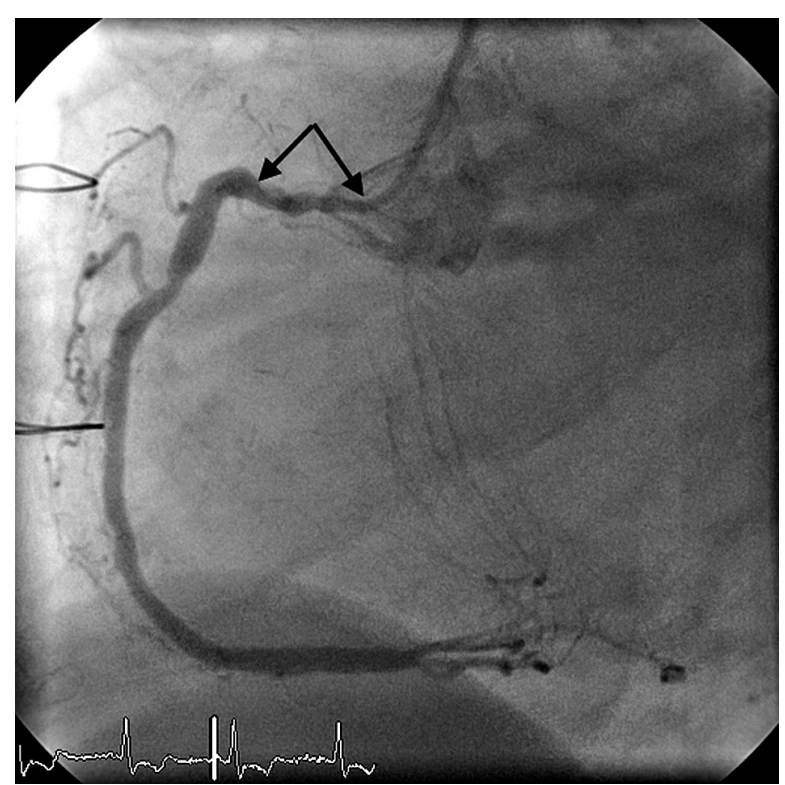

Figure 6. Significant stenosis of the right coronary artery

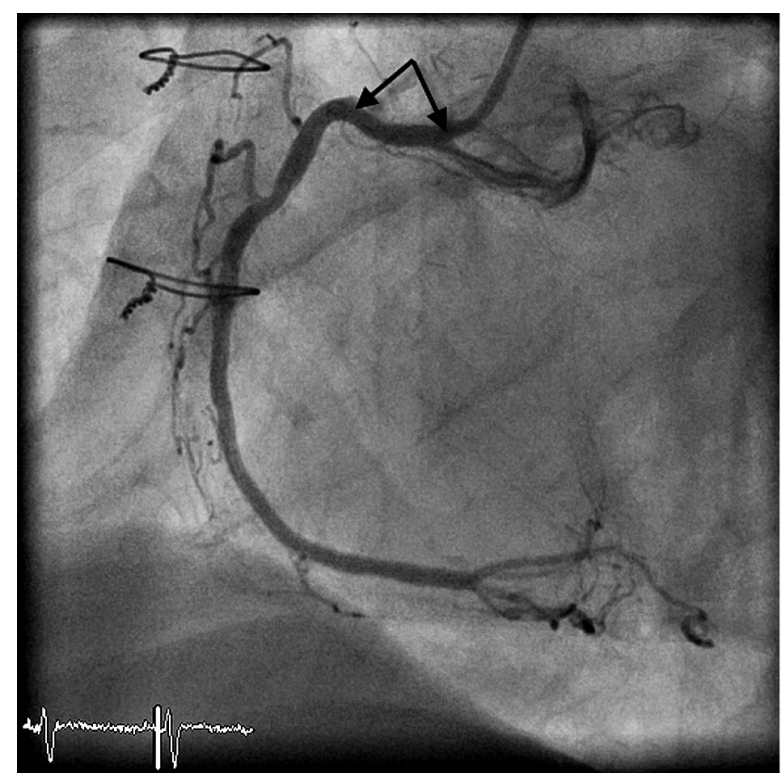

Figure 7. Right coronary artery after stent implantation

\section{Discussion}

Occurrence of symptomatic stenosis of the left subclavian artery (the most common location of stenosis of the aortic arch arteries) is not well defined and happens in $15 \%$ to $25 \%$ of all left subclavian artery strictures $[4,5]$. Stenosis of the subclavian artery may cause serious clinical symptoms. Apart from neurological steal syndrome, critical upper limb ischaemia and cardiac ischaemia in patients who have undergone a bypass between this artery and the coronary artery may also be present. Coronarysubclavian steal syndrome was first described in 1977 [6]. It occurs in $0.44 \%$ of patients who undergo coronary angiography after coronary bypass surgery [6-8]. This condition develops usually a few months after cardiac surgery intervention. Steal syndrome is defined as decreased blood flow through the bypass (internal thoracic - coronary artery) or inversed blood flow, resulting from stenosis of the proximal part of the left subclavian artery [9]. In the majority of described cases, inversed blood flow within the left internal thoracic artery was diagnosed on angiography [9-13]. Hence, to meet classical angiographic criteria, documentation of inversed blood flow from the coronary towards the internal thoracic artery used to be a must. In our case this criterion could not have been fulfilled, as the descending anterior branch of

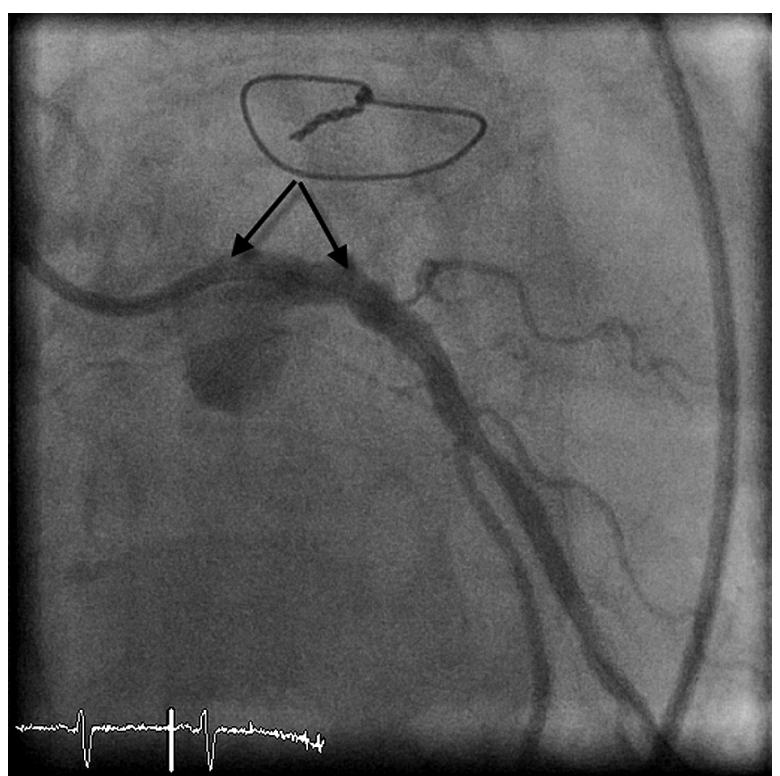

Figure 8. Stent implanted at the trunk of the left coronary artery and proximal part of the circumflex branch 
the left coronary artery did not contrast from the coronary trunk (i.e. it was obliterated), and angiography showed correct direction of severely impaired blood flow (significant delay in artery contrasting). Similar findings were discovered by other authors, who classified them as subclavian-coronary steal syndrome [9]. Regardless of the chronic character of cardiac ischaemia symptoms in a majority of cases, some patients may develop an acute coronary syndrome [9-11, 14]. This was actually the case of the patient described herein, or at least his symptoms of acute coronary insufficiency were aggravated by coexistent stenosis of the subclavian artery.

Cardiac ischaemia in subclavian-coronary steal syndrome is usually accompanied by abnormal blood supply to the left upper limb. A difference in blood pressure taken on each arm is described most often. Data from the literature vary significantly. Some authors were unable to confirm a difference in blood pressure in their patients [9]. Others noted a minor decrease of the pressure taken on the left arm: 25-30 $\mathrm{mmHg}$ in systole and 5-10 $\mathrm{mmHg}$ in diastole $[11,12,15]$. Sometimes however, this difference can be significant: up to $60-85 \mathrm{mmHg}$ in systole and $30 \mathrm{mmHg}$ in diastole $[9,10]$. The blood pressure on the left arm of the patient described above was undeterminable despite relatively minor clinical symptoms. The range of blood pressure difference may result not only from the degree of stenosis, but from the blood pressure of each individual patient as well. Normalization of the blood pressure in patients with subclavian-coronary steal syndrome rarely caused significant clinical symptoms. A few publications note claudication of the left upper limb [10, 11, 14]. Routine examination of the blood pressure on both arms is supposed to identify a group of patients in whom subclavian stenosis is likely [15]. This particularly concerns patients with a difference of blood pressure of more than $20 \mathrm{mmHg}$. In these patients coronary arteriography ought to be supplemented with aortic arch imaging [15]. However, identical bilateral pressure on upper limbs confirmed prior to cardiac surgery does not preclude a possibility of development of steal syndrome during the post-operative course $[11,14]$.

Traditional surgical methods of treatment for subclavian-coronary steal syndrome involve a bypass from the left common carotid artery and left subclavian artery $[12,14,15]$. As in other diseases formerly treated with surgery, such as portal hypertension, progress in minimally invasive techniques brought about a change in treatment of this syndrome. Intravascular methods were applied for both aforementioned nosologies [16, 17]. The possibility of percutaneous angioplasty of the subclavian artery in subclavian-coronary steal syndrome was shown for the first time in 1991 [16]. This procedure is more and more often offered as a method of choice [9-11]. It provides excellent results with relatively small risk of restenosis of $18 \%[7,9]$. Besides, as in the patient described above, intravascular methods give an opportunity to correct recurrent strictures of coronary vessels.

\section{Conclusions}

1. Difference of blood pressure between upper limbs in a patient scheduled for coronary angiography urges verification of condition of subclavian arteries.

2. The finding of subclavian artery stenosis which could have resulted in subclavian-coronary steal syndrome prior to cardiac surgery is an indication to begin treatment with intravascular correction of the subclavian artery.

3. In subclavian-coronary steal syndrome diagnosed after cardiac surgery, percutaneous intraluminal angioplasty of the subclavian artery and correction of coexistent strictures of coronary arteries is a treatment of choice.

\section{References}

1. Ogus TN, Basaran M, Selimoglu O, et al. Long-term results of the left anterior descending coronary artery reconstruction with left internal thoracic artery. Ann Thorac Surg 2007; 83: 496-501.

2. Fiore AC, Naunheim KS, Dean P, et al. Results of internal thoracic artery grafting over 15 years: single versus double grafts. Ann Thorac Surg 1990; 49: 202-8.

3. Sayari R, Upp JR, Wolma FJ. Coronary-subclavian Steal syndrome following coronary artery bypass grafting. Cardiology 1991; 98 : 53-7.

4. Fields WS, Lemak NA. Joint study of extracranial arterial oclucion VII Subclavian steal: a review of 168 cases. JAMA 1972; 222: 1139-43.

5. BA Perler, Williams GM. Carotid-subclavian bypass - a decade of experience. J Vasc Surg 1990; 12: 716-23.

6. Tyras DH, Barner HB. Coronary-subclavian steal. Arch Surg 1977; 112: $1125-7$.

7. Wholey MH, Wholey MH, Postoak D, Ferral H. Techiniques and results treating leasions of the vertebral and great arteries. Paris Course on Revascularization 2004; 354-64.

8. Westerband A, Rodriguez JA, Ramaiah VG, Dietrich EB. Endovascular therapy in prevention and management of coronary-subclavian steal. J Vasc Surg 2003; 38: 699-703. 
9. Wallis F, Kidney D, Molloy M. Percutaneous transluminal angioplasty of subclavian stenosis to improve inflow to internal mammary coronary arterial grafts. Eur Radiol 1996; 6: 220-3.

10. Latacz P, Rostoff P, Rudnik A, et al. Przezskórna rewaskularyzacja podostrego zamknięcia lewej tętnicy podobojczykowej manifestujacego się jako ostry zespół wieńcowy u chorego po zabiegu pomostowania aortalno-wieńcowego. Kardiol Pol 2010; 68: 226-9.

11. Gessner C, Güttler A, Hammerschmidt S, et al. Rare cause of pectangina after coronary artery surgery. Internist 2005; 46: 913-6.

12. Bilfinger TV. Coronary steal syndrome following internal mammary artery bypass surgery: incidence and recommendations for avoiding it. Schweiz Med Wochenschr 1989; 119: 318-21.

13. Kneale BJ, Irvine AT, Coltart DJ. Coronary subclavian steal syndrome following coronary by-pass surgery. Postgrad Med J 1996; 72: $358-60$

14. Olsen CO, Dunton RF, Maggs PR, Lahey SJ. Review of coronarysubclavian steal following internal mammary artery-coronary artery bypass surgery. Ann Thorac Surg 1988; 46: 675-8.

15. Marshall WG Jr, Miller EC, Kouchoukos NT. The coronary-subclavian steal syndrome: report of a case and recommendations for prevention and management. Ann Thorac Surg 1988; 46: 93-6.

16. Ishii K, Hirota Y, Kita Y, et al. Coronary-subclavian steal corrected with percutaneous transluminal angioplasty. J Cardiovasc Surg 1991; 32: 275-7.

17. Bakoń L, Kwaśniewska-Rutczyńska A, Żmigrodzka A, et al. Leczenie nadciśnienia wrotnego przedwątrobowego metodami radiologii interwencyjnej - opis przypadków. Wideochirurgia i inne techniki małoinwazyjne 2006; 1: 163-74. 